\title{
Rewards, risks, and responsibilities of globalization for the cardiothoracic surgeon
}

Richard A. Jonas, MD

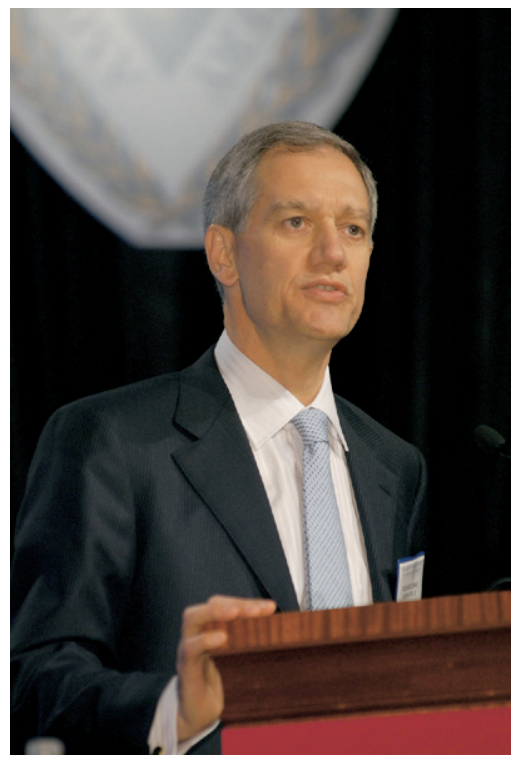

Dr Jonas

From the Department of Cardiac Surgery, Children's National Heart Institute, Children's National Medical Center, Washington, DC.

Read at the Eighty-sixth Annual Meeting of The American Association for Thoracic Surgery, Philadelphia, Pa, April 29-May 3, 2006.

Received for publication Sept 15, 2006; accepted for publication Sept 19, 2006.

Address for reprints: Richard A. Jonas, MD, Chief, Cardiac Surgery, Co-Director, Children's National Heart Institute, Children's National Medical Center, Washington, DC 20010 (E-mail: rjonas@cnmc.org).

J Thorac Cardiovasc Surg 2007;134:1-14

0022-5223/\$32.00

Copyright (C) 2007 by The American Association for Thoracic Surgery

doi:10.1016/j.jtcvs.2006.09.067
$\mathrm{I}$ $\mathrm{t}$ is a tremendous honor for me to be standing before you today as the 87th president of this august and proud academic organization. I am truly humbled to be here standing on the shoulders of giants, individuals of vision and energy who have shaped this Association to be what it is today. This Association is a brilliant public symbol of the importance of the academic mission for the present and future of cardiothoracic surgery. By awarding membership, the Association pays tribute through peer recognition to those who make significant contributions to teaching, research, and clinical surgery. When I became a member of the Association, I considered it one of the greatest honors of my professional career. As a foreign medical graduate from Adelaide, South Australia, to be president of this Association feels like the ultimate realization of the American dream, proof that all doors are open in this great land of opportunity.

I am not alone on this podium this morning. There are many wonderful people who share this honor with me today: first and foremost, my immediate family, my three children, Andrew, Michael, and Nicole Sofia, of whom I am tremendously proud, and my beautiful, loving wife, Katherine, who has counseled and supported me through the challenges and complexities of life, as well as my extended family, all of whom live in Australia. My assistant for 23 years, Laura Young, has quietly and calmly managed my increasingly complicated life with the most remarkable efficiency and organization. Laura's vast memory not only includes details of grant deadlines and council meetings but also extends to remembering touching personal details of patients and their families from decades ago. Surely one of the great joys of being a congenital heart surgeon is that most of our patients lead long and productive lives, so that over time we accumulate a vast extended family. The holidays are a wonderful time when cards arrive from around the country and around the world. The support and encouragement of so many of these families is also with me this morning.

I mentioned this morning in my introduction my gratitude for the managerial efficiency of our management organization, the Professional Relations and Research Institute of Boston. I am also indebted to the council members and officers of the The American Association for Thoracic Surgery (AATS) (Figure 1). I would also like to thank Dr Andrew Wechsler, the Editor of the Journal of Thoracic and Cardiovascular Surgery, who will be stepping down at the end of next year. Under his direction the Journal has been nurtured through a tremendously demanding time of transition from paper to electronics. Not only has this been accomplished with efficiency and intelligence but, in addition, the academic rigor, innovation, and readability of the Journal have never been better.

At the Children's National Medical Center in Washington, DC, which has been my home now for nearly 2 years, it has been a pleasure to work with an outstanding group of individuals. I am particularly fortunate to be working with Dr Gerard 


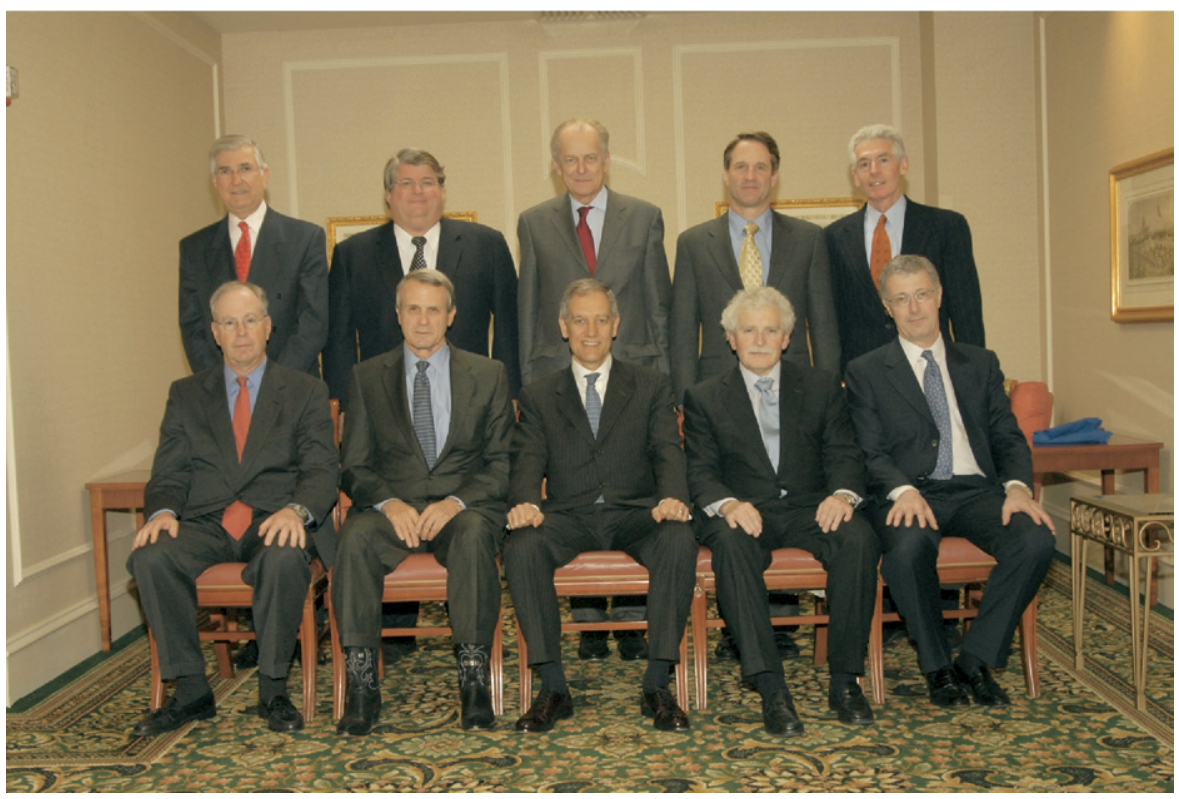

Figure 1. The 2005/2006 Council of the AATS.

Martin, who is co-director of the Heart Institute and chief of cardiology (Figure 2). The relationship between cardiology and cardiac surgery can be a fragile one, particularly in an area of shifting finances and power within the hospital structure. Today we are collectively successful in shepherding children with congenital heart disease through even very complex reconstructions with an overall success rate approaching $98 \%$ to $99 \%$. However, this results in a cumulative pool of patients needing life-long follow-up with cardiology but, ideally, rarely if ever with cardiac surgery. Within my professional lifetime, congenital cardiology departments have grown from being equal partners to being up to 10 times as large as surgical departments in terms of numbers of physicians and with increasing financial disparity. This is leading to stresses within congenital cardiac programs. But such stresses can be minimized by an administrative structure such as exists at Children's National

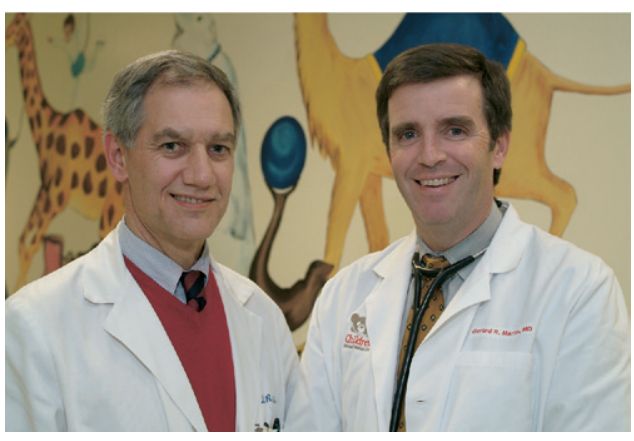

Figure 2. The author (left) and Gerard Martin, MD, co-directors of the Children's' National Heart Institute, Washington, DC.
Medical Center, where all decisions as well as hospital and professional revenues are managed collectively by the physician and administrative staffs.

\section{A Tribute to My Mentors}

My journey to this podium has been a long one, but it has also been enormously satisfying and rewarding. As surgeons we are blessed to have families place in our hands the responsibility of caring for their loved ones. We have an opportunity to practice both an art and a science, to enjoy the consummate satisfaction of applying practiced physical skills and the fundamentally humane activity of supporting and encouraging and sometimes grieving with families who are passing through an incredible period of stress in their lives.

My journey to this podium would not have been possible without the support of my surgical mentors, to whom I would now like to pay tribute and give thanks by briefly tracing my educational progress halfway around the world. My mentors worked within quite different health care delivery systems. My direct experience with these different systems has no doubt shaped my views of the global challenges and opportunities facing cardiothoracic surgeons that I will share with you this morning.

My journey began in Adelaide, South Australia, best known as the home of the Australian wine industry (Figure 3). As a medical student at the University of Adelaide, I worked within a health care system that in those years was a reasonably successful balance of private and public funding. However, in the tradition of the British model, private and public patients were segregated into private versus govern- 


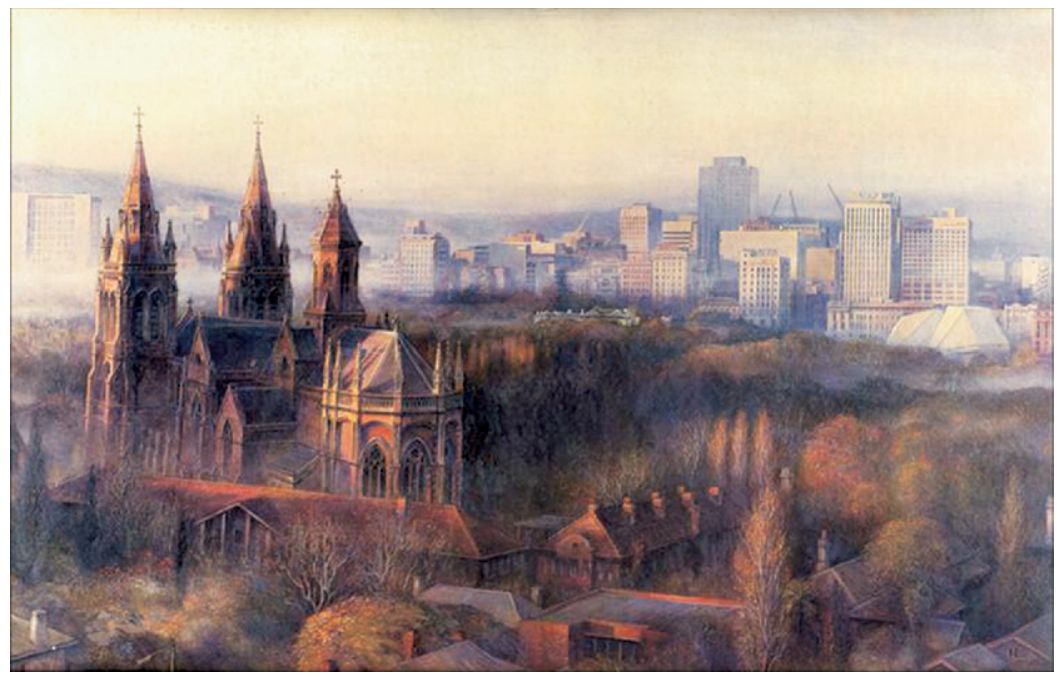

Figure 3. Adelaide, capital of the Australian state of South Australia. Adelaide First Light, Kenneth Jack, 1977.

ment hospitals. One clear lesson that I took away from that experience was that if ever I was to be undertaking complex surgery in patients who would require intensive care management postoperatively, I would confine my practice to one hospital. This principle was reinforced by my mentor and good friend, Dr D'Arcy Sutherland, who established open heart surgery in Adelaide and who set me on the road to this podium (Figure 4). D'Arcy was a master surgeon, a tremendously successful administrator, and one of the first in the world to recognize the importance of the careful collection of risk-adjusted registry data. At the very first AATS meeting that I attended in San Francisco in 1980, D'Arcy was the honored guest speaker. D'Arcy is alive and well in Adelaide and sends his best wishes to his many friends in the AATS (Figure 5).

During my medical student years I had the opportunity to work for 3 months in the National Health Service in the

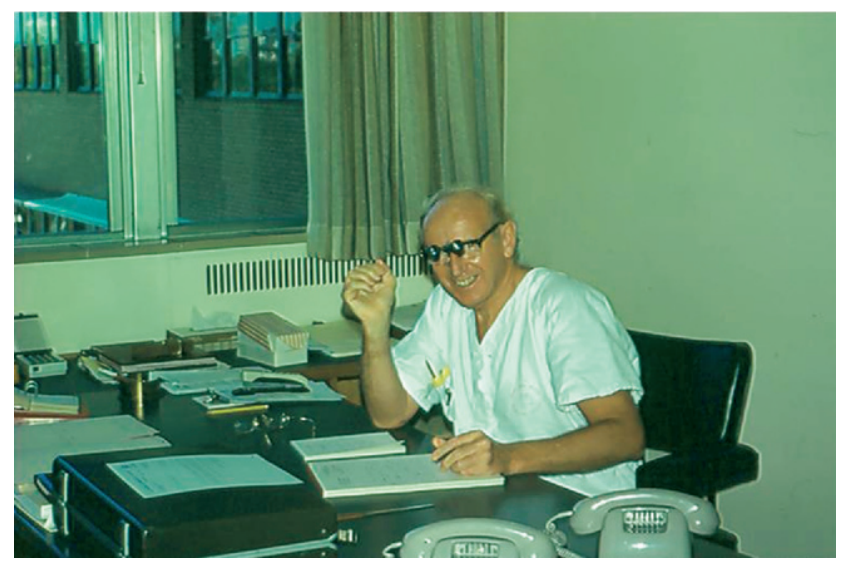

Figure 4. H. D'Arcy Sutherland, a pioneer of heart surgery in Australia and past president of the Australian College of Surgeons.
United Kingdom. I was surely in the trenches of the $\mathrm{Na}$ tional Health Service in the Derby City Hospital in the Midlands of England treating coal miners and the artisans who crafted Royal Crown Derby china. This was during the winter of discontent in 1973 when the Heath government was collapsing, the miners were on strike, British Rail was on strike, and the National Health Service was facing major

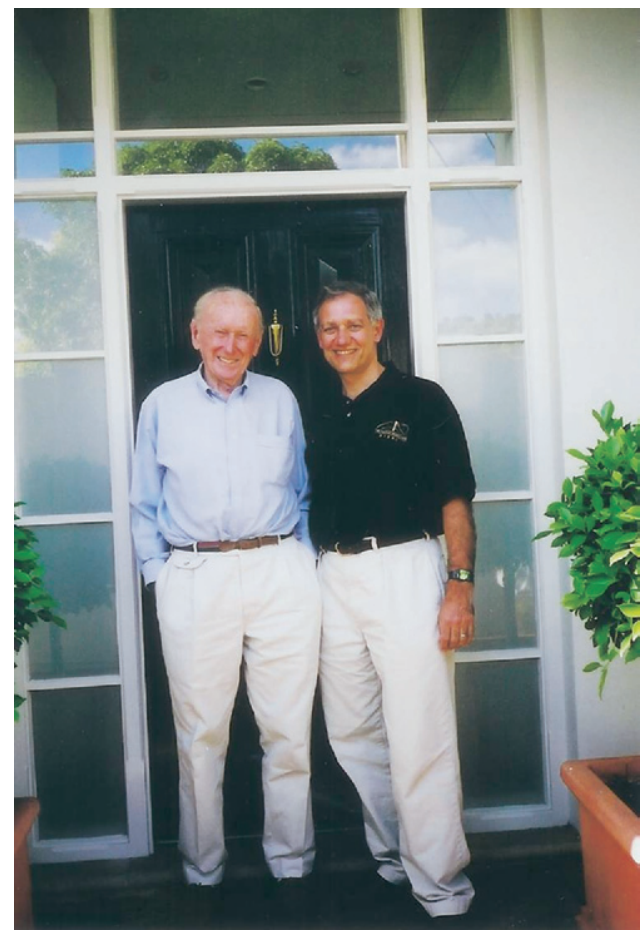

Figure 5. The author (right) with Dr D'Arcy Sutherland in Adelaide, South Australia, 2004. 


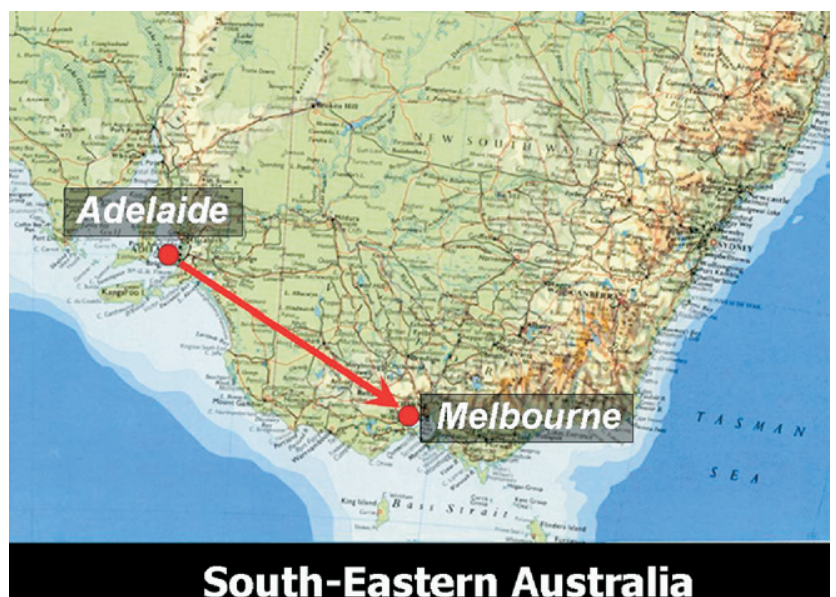

Figure 6. Melbourne is the capital of the Australian state of Victoria.

fiscal challenges. The experience taught me a lot about big government.

I also had the opportunity in 1974 to spend a month in mission hospitals in northern New Guinea. New Guinea was in a transition phase between colonial government by Australia and independence. I worked with a fascinating mix of missionary zealots, kind and humane physician philanthropists, and lunatics. I learned much about human nature and, just as important, I learned about the challenges facing nongovernment organizations that provide care to indigenous populations, the challenge of education versus dependency.

In Melbourne, Australia, 500 miles southeast of Adelaide (Figure 6), I undertook my general surgical training at the

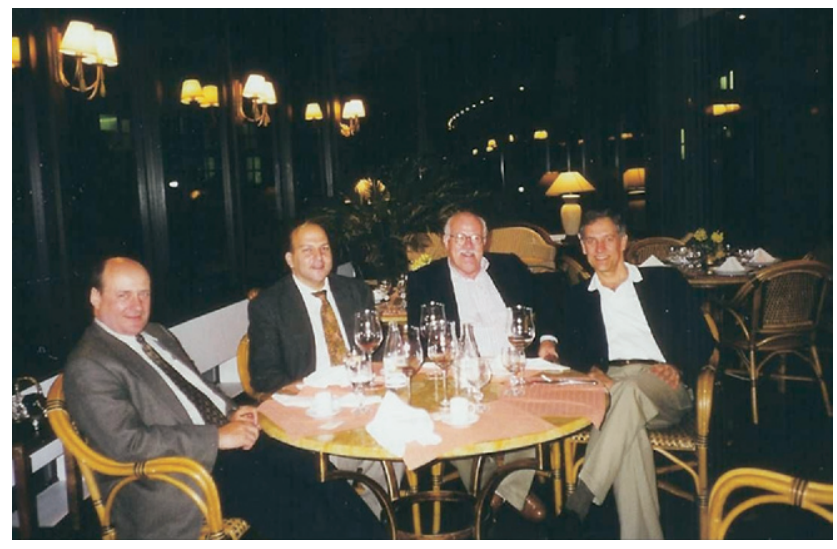

Figure 8. Roger Mee, MD, at left, past director of the Royal Children's Hospital, Melbourne, Australia, with Fabio Sallum, MD, Milton Meier, MD, both of Brazil, and the author.

Royal Melbourne Hospital, one of the great academic institutions of Australian medicine, where I had the pleasure of working with Brian Buxton and Jim Tatoulis (Figure 7). I began my cardiothoracic training at the Melbourne Children's Hospital, to which D'Arcy Sutherland had been called in from Adelaide to resuscitate a badly ailing congenital cardiac program. D'Arcy began by recruiting the great surgical technician Dr Roger Mee (Figure 8). This was the first of many opportunities where I witnessed how fragile a congenital cardiac program can be and the care that is needed to build cohesion between surgeons, cardiologists, intensivists, anesthesiologists, and the entire health care team that makes up a congenital cardiac program.
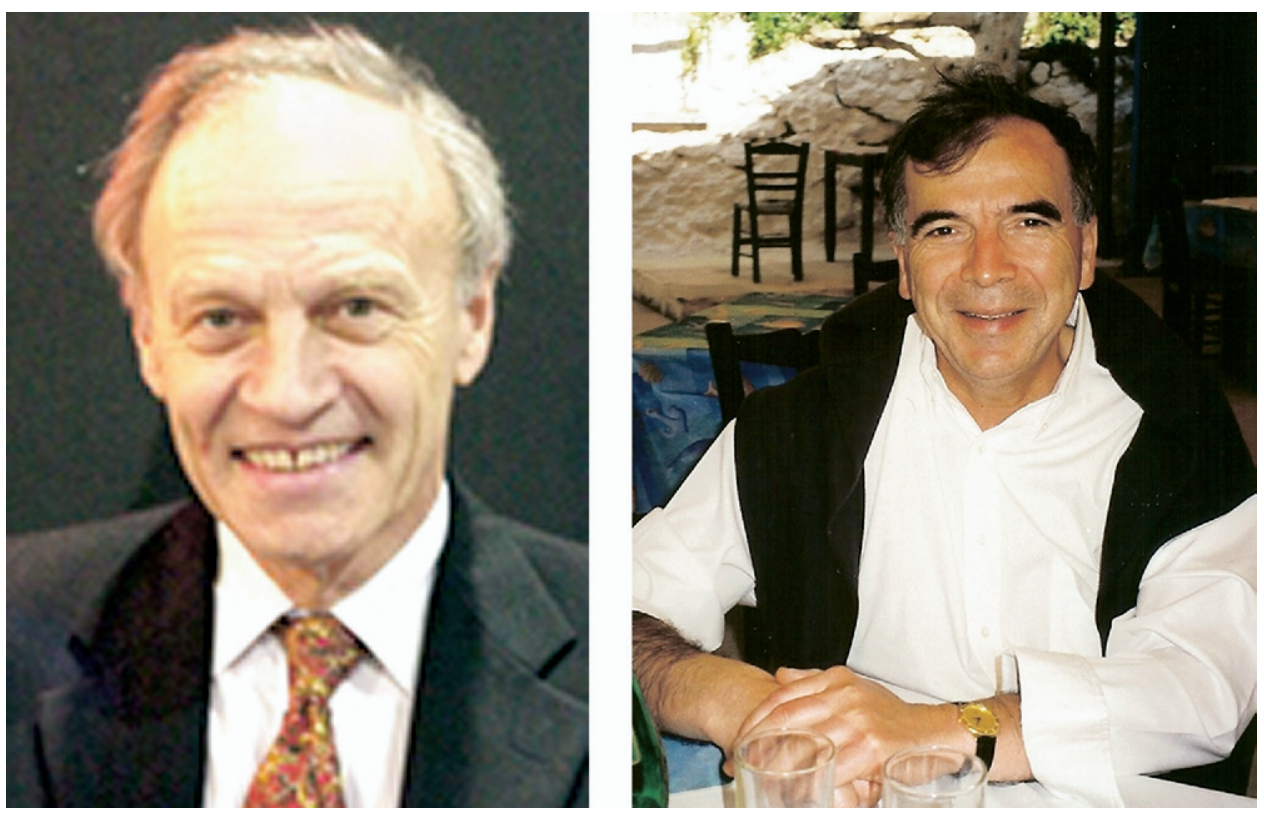

Figure 7. Brian Buxton, MD (left), director of cardiothoracic surgery at the Austin Hospital, Melbourne, and James Tatoulis, MD (right), director of cardiothoracic surgery at the Royal Melbourne Hospital, Melbourne, Victoria, with whom the author trained at the Royal Melbourne Hospital.

4 The Journal of Thoracic and Cardiovascular Surgery • July 2007 


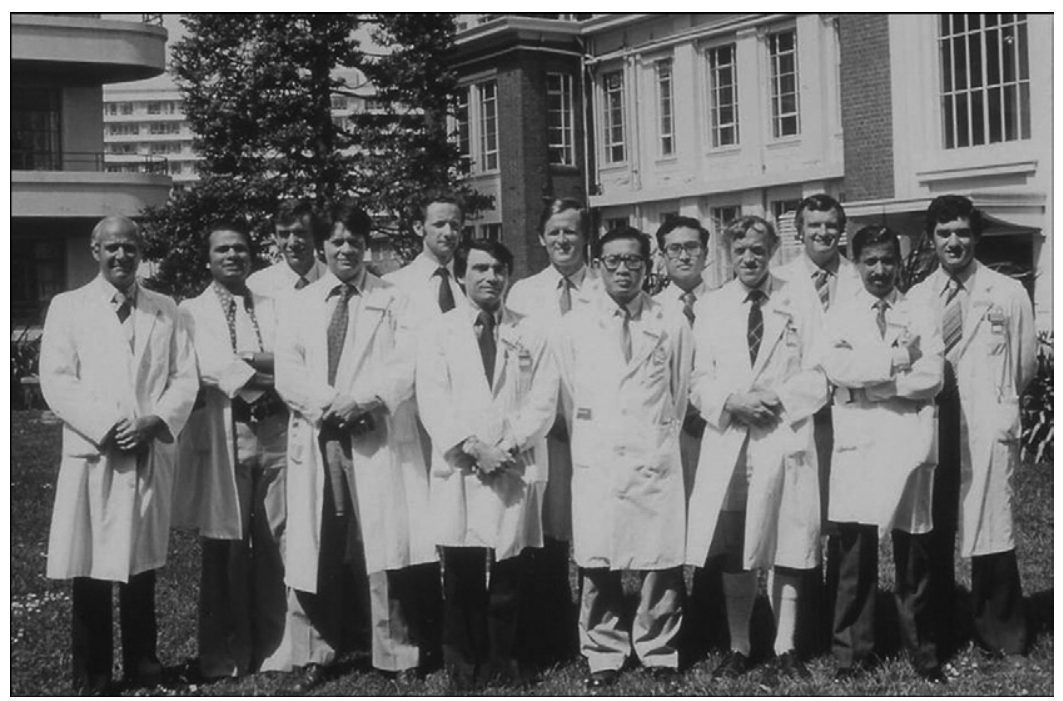

Figure 9. Staff and trainees of the Green Lane Hospital Open Heart Surgery Unit, Auckland, New Zealand. Alan Kerr, MD, is third from left.

I continued my journey eastward to Auckland, New Zealand, where I worked with the surgical master Sir Brian Barratt-Boyes and his dedicated team, including Alan Kerr at Green Lane Hospital (Figure 9). I was extremely saddened by the recent loss of Sir Brian (Figure 10) and extend my condolences to his wife, Sarah. Working in New Zealand allowed me to witness once again the risks inherent in a fully nationalized health system when a country runs into economic difficulty, as was the case in New Zealand in the early 1980s.

Brigham \& Women's Hospital in Boston (Figure 11), the next stop on my journey, was a sharp contrast to the nationalized health care system of New Zealand. Dr Larry Cohn and Dr Jack Collins, as well as my peer, Richard Shemin, who went on to head up the Boston University

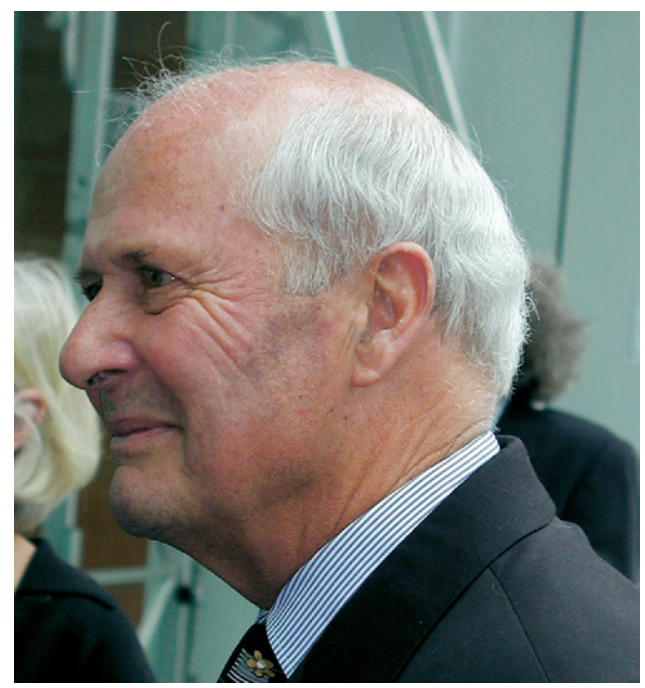

Figure 10. Sir Brian Barratt-Boyes. Used with permission from Dr Randolph Chitwood.
Program, all became close friends and mentors and demonstrated the efficiency and superb high standards that the US health care system could achieve. I was particularly impressed to find that there was no distinction between private and public patients. In fact, this concept really did not exist in the United States, and in those days the nonprofit academic health care system in Boston was about as egalitarian as one could possibly hope for.

Drs Cohn and Collins arranged for me to work at the Children's Hospital in Boston, where Aldo Castaneda and Bill Norwood (Figure 12) were in the process of building a great regional congenital heart program on the solid foundation laid by Robert Gross. They achieved this through innovation, courage, and persistence in the face of intense criticism. It was a hugely important experience for me to be a part of the development of the Norwood procedure for hypoplastic left heart syndrome and the neonatal arterial switch procedure. I learned a lot about how surgical programs can weather the challenges that arise with innovation.

During my 22 years at the Boston Children's Hospital, I worked with many enormously talented individuals. One of my two senior partners, Dr John Mayer, whom I was fortunate to retain on staff after I became chief of the department in 1994, has made many contributions to congenital coding and reimbursement. Dr Pedro del Nido, whom I recruited from Pittsburgh, is currently chair of our AATS scientific and government relations committee and is helping to lead the defense against the contraction of funding for cardiothoracic surgical research. This work is vital because there is no question that many forces are at work threatening academic institutions and academic surgeons. It is the role of a professional association such as the AATS to advocate for academic surgeons and institutions to protect our mis- 


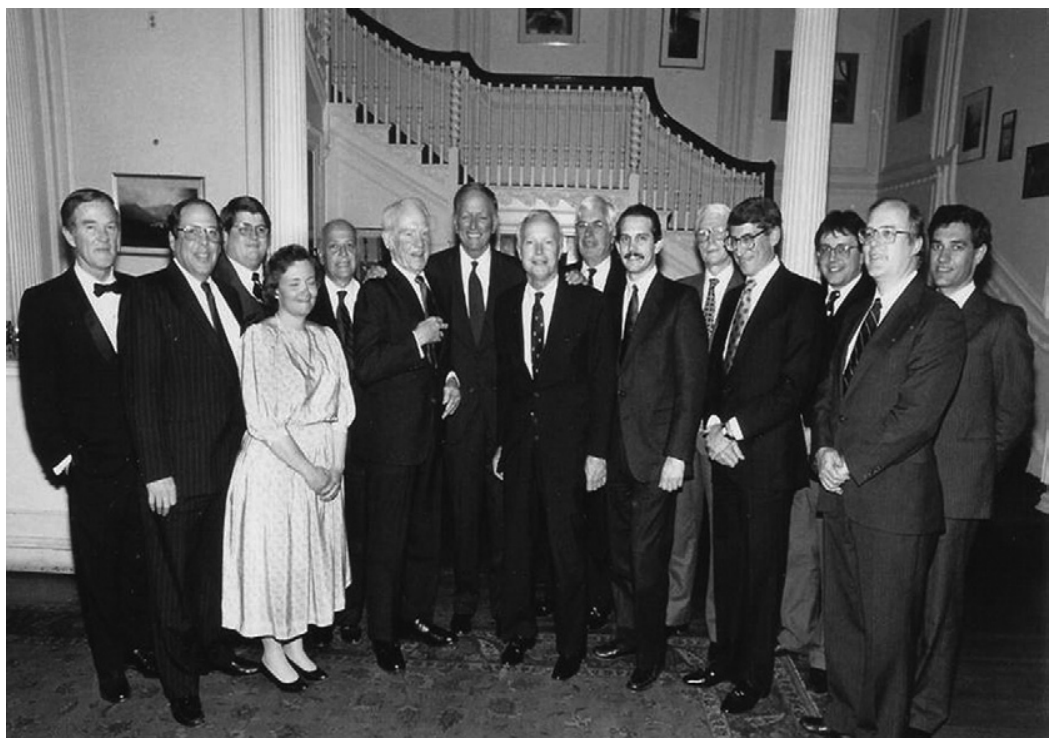

Figure 11. Harvard-based cardiothoracic surgeons honor Denton Cooley. Dr Dwight Harken, pioneer of cardiac surgery at Brigham \& Women's Hospital, is on Dr Cooley's right. Dr Jack Collins is at far right, and Dr Larry Cohn is back row, fourth from left.

sion of advancing the field and training the next generation of cardiothoracic surgeons.

\section{The Teaching of Cardiothoracic Surgery}

There is no question that the teaching of cardiothoracic surgery is a complex task (Figure 13). We teach through our personal example, through our mentoring in the operating room, and through the dissemination of new concepts, new techniques, and the introduction of new technology at meetings such as this. We teach through the writing of original journal articles and book chapters, through the editing of books and journals, and through peer review of publications such as the Journal of Thoracic and Cardiovascular Surgery. We must reward such activities by mechanisms such as the distinguished reviewer award recently introduced in the Journal of Thoracic and Cardiovascular Surgery.

But associations such as the AATS cannot do it alone. We must work with the collaboration and cooperation of teaching institutions, which must continue to provide incentives and opportunities for adequate instruction of the next generation. This was an easy decision for institutions when there was no limit on the number of hours that a resident

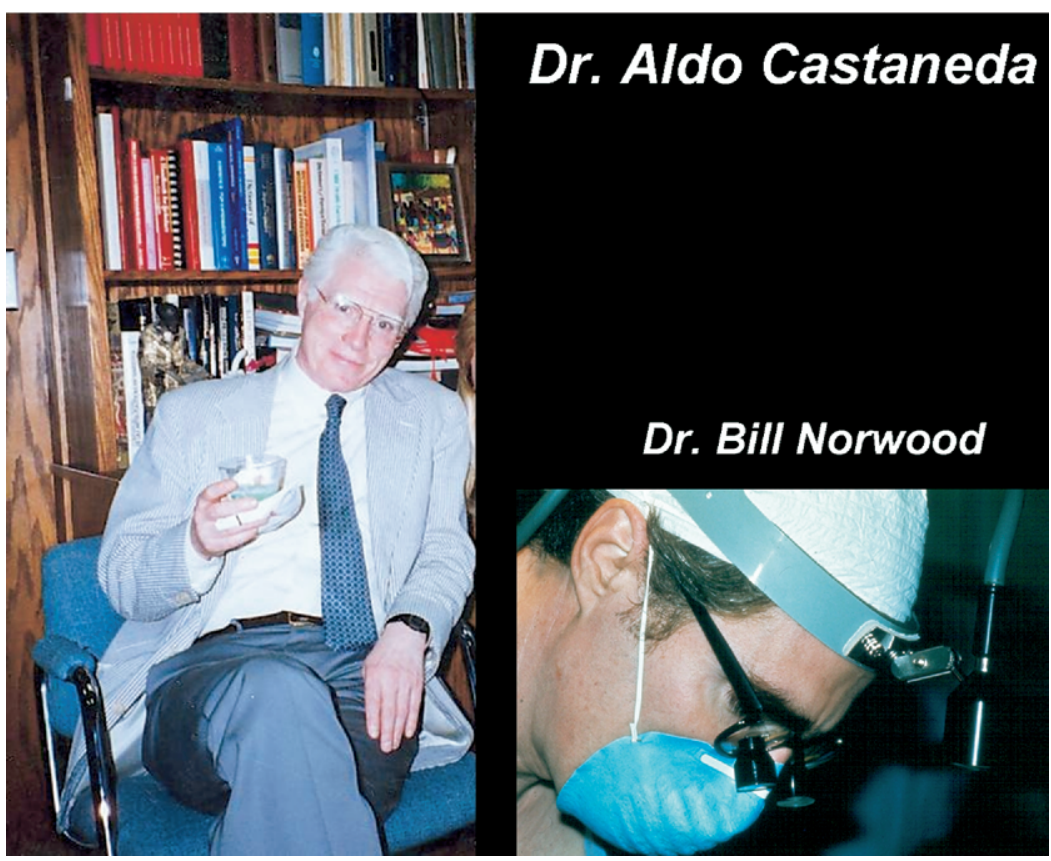

Figure 12. Dr Aldo Castaneda (left) and $\mathrm{Dr}$ William Norwood (right), Children's Hospital Boston.

6 The Journal of Thoracic and Cardiovascular Surgery • July 2007 


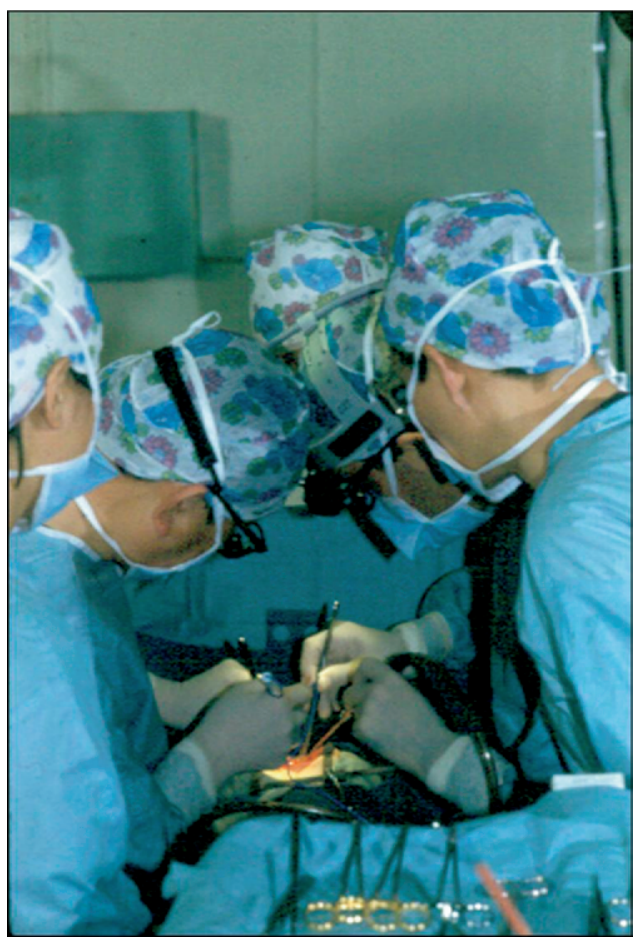

Figure 13. The author operating at Xin Hua Hospital, Shanghai, China, with Dr Ding Wen Xiang and Dr Su Zhao Kang.

could work and reimbursement through the Medicare program was generous. However, the current total costs of training are now being carefully factored into the economic analysis of the productivity of clinicians.

\section{The Problem of Projecting Manpower Needs}

One of the other great challenges facing cardiothoracic surgical educators is the difficulty predicting the manpower needs for our specialty at the end of a very long training process. How many surgeons should we be training today? Like many of you in this auditorium, my surgical training extended over 9 years. What will our manpower needs be in 9 years' time? This is a remarkably difficult question to answer for a host of reasons, but it is a question that we are obliged to answer. Cardiothoracic training is still ultimately a mentorship, and there is a fundamental obligation on the part of the mentor to assist the trainee to have a productive and satisfying position at the end of the training process. For many years the AATS and the Society of Thoracic Surgeons have collaborated in intramural workforce studies. Recently, in addition, we have commissioned the American Association of Medical Colleges to undertake a review to try to help us understand the impact of the many external forces that are likely to influence our manpower needs. These factors include demographic shifts such as the aging

\section{Area of Subspecialty of Registrants AATS Annual Meeting 1998}

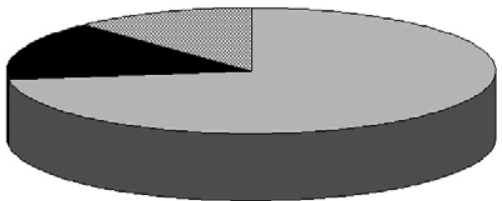

$\square$ Adult Cardiac

- General Thoracic

Dongenital

Figure 14. Classification of attendees at a recent AATS meeting broken down by subspecialty.

of the US population as well as technical innovations in our own and other medical specialties.

The relatively recent subspecialization of cardiothoracic surgery into adult cardiac, general thoracic, and congenital has undoubtedly complicated the projection of manpower needs (Figure 14). The percentage of female physicians within the specialty has remained less than $5 \%$. This statistic unique to our specialty has become increasingly important as the percentage of female graduates from medical schools has risen to greater than $50 \%$.

\section{The Globalization of Cardiothoracic Surgery}

If it is to be truly informative, the manpower study will need to look beyond the shores of the United States. All of us are working within an increasingly interconnected global society. Just look at some data that are of great importance to the financial health of this Association. More than 50\% of attendees at this meeting over the past 10 years have been non-US physicians (Figure 15). In other words, this meeting would be half its size without the international attendees.

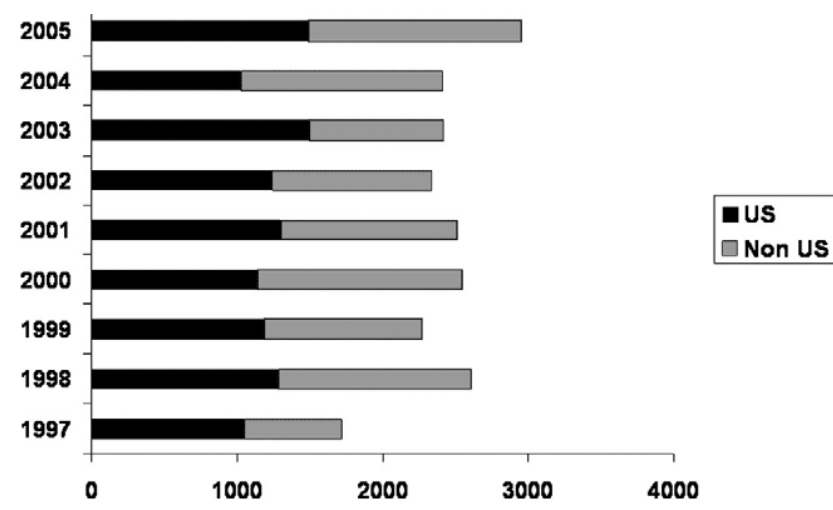

Figure 15. Attendees at the AATS meeting, United States versus non-United States, 1997 to 2005. 


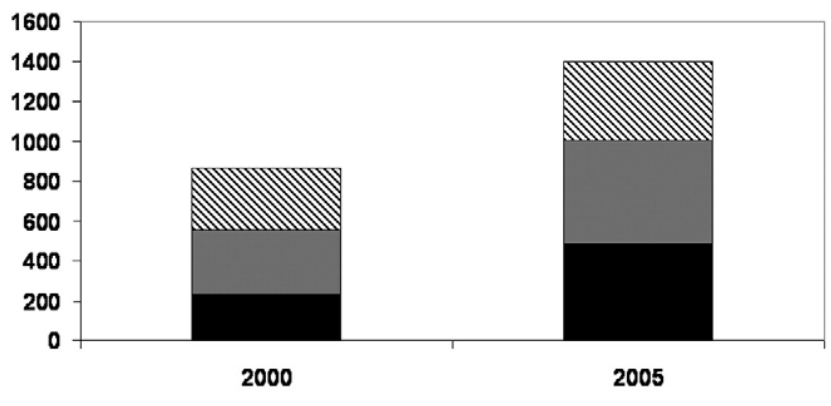

Asia, Middle East, Australia $\square$ Europe $\mathbb{Q}$ USA/Canada

Figure 16. Manuscripts submitted to the Journal of Thoracic and Cardiovascular Surgery by region of origin, 2000 versus 2005.

The same shifts can be seen in the submission and acceptance of manuscripts for our Journal (Figure 16).

The AATS has responded to the internationalization of this meeting and the Journal in several ways. One of the members of the Council is now appointed from among the international members. We thank Marko Turina for the superb job that he has done in this position. Last year, the Council voted to eliminate US citizenship requirements for new members. In fact, the membership committee has been charged with increasing the international representation among the membership. The conversion of the Journal to an electronic format that is available globally brings distant countries closer to us, such as Australia and New Zealand, where the journal previously arrived more than 2 months after publication. At this meeting, we have instituted a global session that will be held again this year on Wednesday morning, organized by Dr Philip Corcoran, the chief of cardiothoracic surgery at Walter Reed Medical Center in Washington, DC, with whom I have the pleasure of working.

Although it is tempting to attribute the growth of the international participation in our meeting and Journal to their academic excellence alone, I believe there are other important factors at work. Despite its contraction in the United States, cardiothoracic surgery is expanding at a prodigious rate in many areas of the world, particularly in India and China. This is primarily a result of economic development in these and many other countries, development which is being fostered by economic globalization. We need to examine how globalization may affect the manpower needs of our specialty, both within the subspeciality areas and for cardiothoracic surgery as a whole. This analysis will also afford us the opportunity to appreciate how globalization is affecting global health overall and the relevance of those changes to us, not just as cardiothoracic surgeons but also as physicians and as members of the human race.

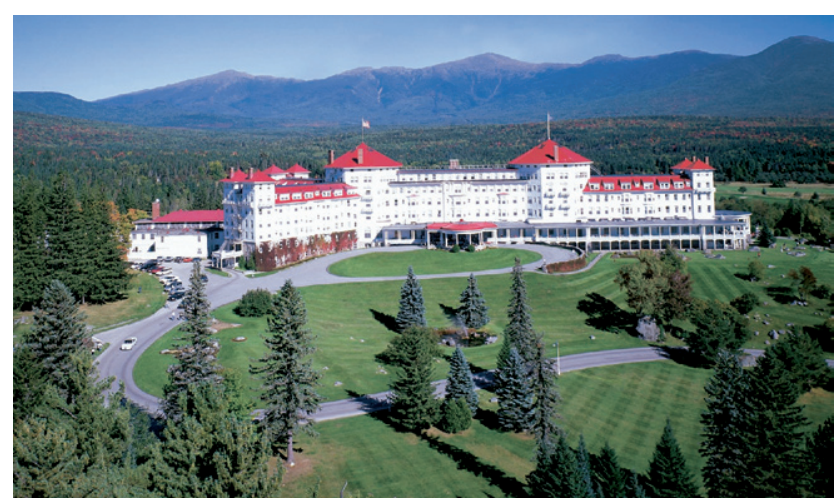

Figure 17. The Mt Washington Hotel in the White Mountains of central New Hampshire was the birthplace of the World Bank, the International Monetary Fund, and the World Trade Organization in July 1944. Courtesy of The Mount Washington Resort at Bretton Woods.

\section{What Is Globalization?}

There are many definitions of globalization, but all of them carry the sense that the world is becoming smaller and we are increasingly interconnected economically, socially, and culturally. The epidemic of severe acute respiratory syndrome (SARS) and the avian flu threat also remind us that health risks have been globalized.

There is a tendency to perceive globalization as a totally new phenomenon, a recent consequence of the Internet, the digitization of data, and the establishment of a global hub-and-spoke air-transportation system. However, viewed from a greater distance, globalization is a continuum that has extended over millennia with the gradual breakdown in local tribalism as transportation and communication have evolved. New Guinea, as I learned when I was there, is a fascinating study of the consequences of difficult communication and transportation resulting from the dense and mountainous jungle terrain. The isolation of individual tribes has been associated with 400 unique languages among New Guinea tribes, which represents the densest concentration of diverse languages of any region of the globe. In contrast, international airline pilots have had to adopt English as a universal global language.

There have been important tipping points in the progress of globalization. In fact, some would say that globalization began with the emergence of intercontinental travel by sail ship and the emergence of the capitalist world system in the 1500s. The industrial revolution and the harnessing of power in the 19th century are cited by others as the origins of globalization. The modern era of economic globalization, however, can be pinpointed with great accuracy both geographically and chronologically. Figure 17 shows the Mt Washington Hotel, nestled in the beautiful White Mountains of central New Hampshire not too far from my own New 


\section{Top Ten Disease Entities in 1990 and 2020 by \% DALY Impact

1990

- 1. Respiratory infection

- 2. Diarrheal disease

- 3. Perinatal illnesses

- 4. Major depression

- 5. Ischemic heart disease
2020

- 1. Ischemic heart disease

- 2. Major depression

- 3. Auto accidents

- 4. Cerebrovascular

- 5. COPD
Figure 18. The Global Burden of Disease Report from 1996 predicted that by 2020 ischemic heart disease would be the number 1 disease entity, as measured by DALY (disability-adjusted life year). COPD, Chronic obstructive pulmonary disease. Data were obtained from Mathers C, Loncar D. Project of global mortality and burden of disease from 2002 to 2030. PLOS Medicine. 2006;3: 2011. Copyright 2006, Public Library of Science.

England home. In July 1944, representatives from the 44 allied nations of World War II, which was still in progress, sowed the seeds for the establishment of the World Bank, the International Monetary Fund, and the World Trade Organization. During the cold war years, these three institutions provided the economic armamentarium whereby Western countries pursued the objective of containing communism by providing loans to developing countries. After the fall of the Soviet Union, however, these organizations adopted a new agenda. The underlying goal has been to reduce global poverty and to improve economic opportunity and productivity throughout the Second and Third Worlds by opening markets, removing trade barriers, and through carefully monitored loans from the developed to the developing world. Supporters of globalization can produce powerful evidence that these goals are being achieved. ${ }^{1,2}$ However, there is another side to the story, as I will examine in a few minutes. First, however, let us look at the health consequences of globalization and what these mean for us as cardiothoracic surgeons.

\section{Demographic Consequences of Globalization}

In the early 1990s, the World Bank commissioned a projected titled The Global Burden of Disease. ${ }^{3}$ This was performed in conjunction with the Harvard School of Public Health and the World Health Organization, the coordinating authority for international public health established by the United Nations in 1948. One important outcome of this study was the development of a new metric, the disabilityadjusted life year, which allows assessment of the effect of disease not only on lifespan but also on health span. In essence, a life can be shortened not only by death but also

\section{Life Expectancy in the US}

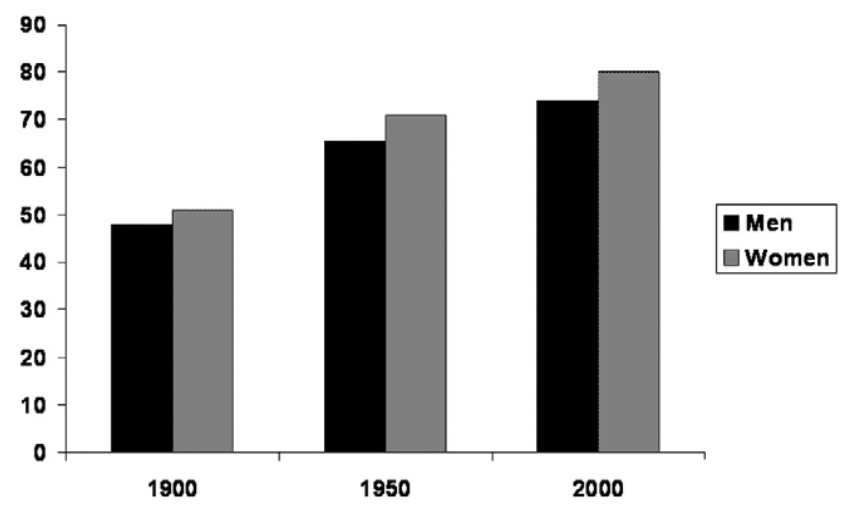

Figure 19. The increase in life expectancy between 1900 and 2000 for American men and women. Data were obtained from Mathers C, Loncar D. Project of global mortality and burden of disease from 2002 to 2030. PLOS Medicine. 2006;3:2011. Copyright 2006, Public Library of Science.

by chronic disability. Figure 18 demonstrates that in 1990, communicable diseases such as respiratory infections remained the most common global cause of death and chronic ill health. However, projections by this study suggest that by 2020 ischemic heart disease will have become the number 1 disease entity, nearly doubling in less than 30 years. Health losses from cancer are also projected to nearly double over the same time frame. Economic development carries with it the consequences of an aging population and the hazards of smoking and high fat, high calorie diets. ${ }^{4}$

\section{Nutrition}

Economic progress in the developing world has been accompanied by the replacement of the traditional diet rich in fruit and vegetables by a diet rich in calories provided by animal fats and lower in complex carbohydrates. It has been reflected in a rapid rise of urban obesity. When I first started visiting China in the early 1980s, there were no obese children. There was only one heavy person at our hospital and that was the cook, who determined that I was going to look like her by the end of our visit with a wonderful diet of dumplings. However, the prevalence of obesity in urban children in China aged 2 to 6 years has increased from $1.5 \%$ in 1989 to $12.6 \%$ in $1997 . .^{5}$ Cooking in the developing world has been altered by the availability of microwave ovens and cheap prepared meals with high fat and caloric content. In the United States, the fast food industry spent 3 billion dollars on television advertising in the year 2000. In the same year, the National Cancer Institute's " 5 a day" program, which encourages the consumption of fruits and vegetables to prevent cancer and other diseases, spent 1 million dollars. ${ }^{6}$ 


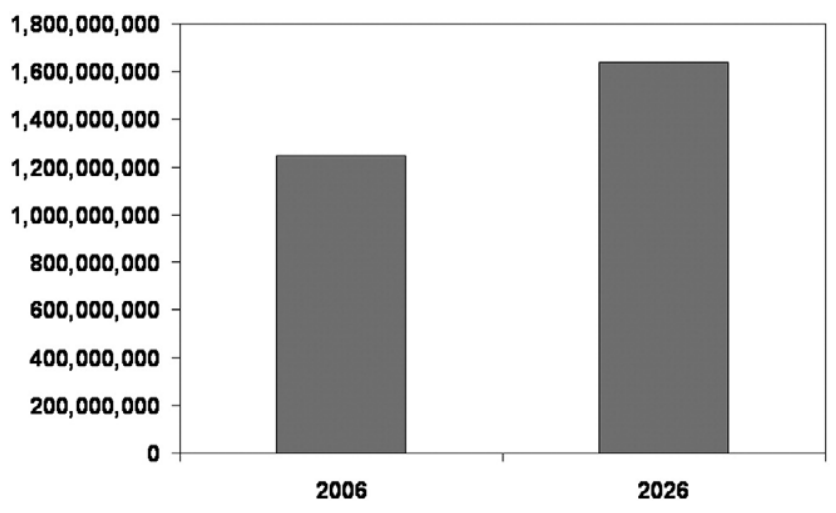

Figure 20. Total number of smokers is projected to increase by more than $30 \%$ globally in the next 20 years. Data were obtained from "Tobacco is impoverishing people and nations, WHO warns" available at http://www.wpro.who.int/NR/rdonlyres/7321AD836AB5-4071-B374-535C243684DA/0/Tobaccolmpoverishing.pdf

\section{Aging}

There is a tendency to focus any discussion of the aging of the general population of the United States on the baby boom generation, the population bulge that will reach 65 in just 5 years in 2011. However, the situation is significantly compounded by the dramatic increase in life expectancy that has occurred over the past 50 years (Figure 19). In the year 2000, Americans enjoyed a life expectancy of almost 77 years. One hundred years ago life expectancy was close to 50 years. Today, individuals who reach age 65 can anticipate a life expectancy of 81 for men and 84 for women. ${ }^{4}$ And for those who live to age 65 , the top two causes of death are heart disease and cancer, followed by stroke, emphysema, and pneumonia. All these conditions share a common risk factor: tobacco.

\section{Tobacco}

Trends in the use of tobacco will have important implications for the burden of cardiovascular and thoracic disease that we will face in the coming years. Although tobacco use in the developed world is declining slowly by about $0.5 \%$ /year, tobacco use in the developing world is rising at nearly 3.5\%/year (Figure 20). ${ }^{4,5}$ Today there are more than 1 billion smokers around the globe with numbers projected to rise by more than $30 \%$ in the next 20 years. And although the large American and British tobacco multinational companies take much of the blame for the rapid current expansion of smoking in the developing world, the fact is that China is overwhelmingly the largest producer of tobacco, producing $36 \%$ of the world's cigarettes in contrast to $11 \%$ produced by the United States. In fact, China and its state-run tobacco monopoly produce more tobacco than the next 6 largest producers combined. ${ }^{4}$

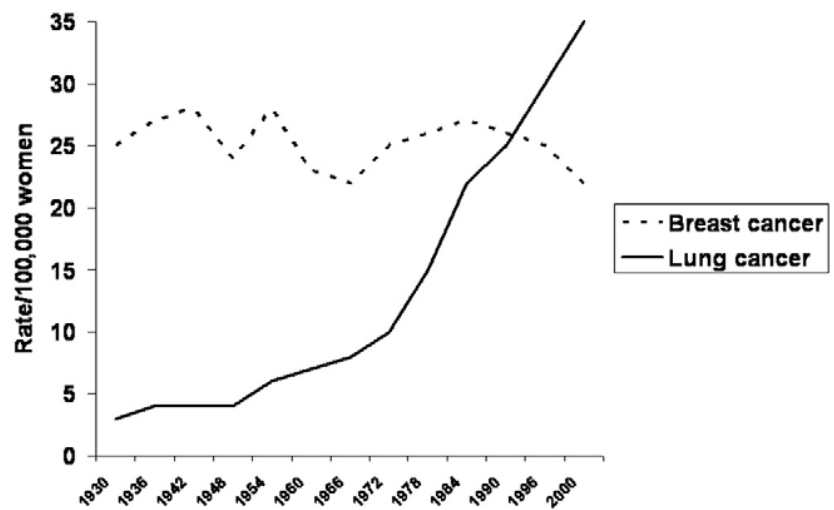

Figure 21. In 2003 there were $\mathbf{2 0 , 0 0 0}$ more deaths among women from lung cancer than from breast cancer. Data were obtained from www.who.int/gender/documents/LungCancerlast2.pdf

\section{Lung Cancer Prevalence}

How will these changing global demographics and practices affect the disease entities most relevant to cardiothoracic surgeons? It is no news to this audience that lung cancer, particularly in American women, has already reached epidemic proportions. Between 1930 and 1997 the death rate from lung cancer among American women increased 6 times. In 2003, there were 20,000 more deaths from lung cancer than from breast cancer among women (Figure 21). ${ }^{4}$ Unfortunately, efforts to reduce smoking rates have been less successful with women than with men. Outside the United States, women are responding to aggressive targeted marketing and joining the ranks of smokers every day. In Japan, smoking among women has doubled over a recent 5 -year period from $9 \%$ to $18 \%$. $^{4}$

\section{Cardiovascular Disease Prevalence}

The dramatic declines in death rates from heart attack and stroke in the United States over the past 50 years have lulled us into a state of complacency and blinded us to a storm that is gathering just over the horizon. The convergence of risk factors, particularly obesity, diabetes, and physical inactivity in the United States and tobacco use, dietary changes, and increased life expectancy globally without question will result in a substantial increase in the global burden of cardiovascular disease.

\section{Congenital Heart Disease Prevalence}

Despite regional variations in environmental factors and genetic makeup, the incidence of congenital heart disease around the world remains consistently at approximately $0.8 \%$ of live births, thereby making it the most common major congenital abnormality. Despite predictions that improved ultrasound methods for fetal diagnosis would result in increased rates of pregnancy termination, the 


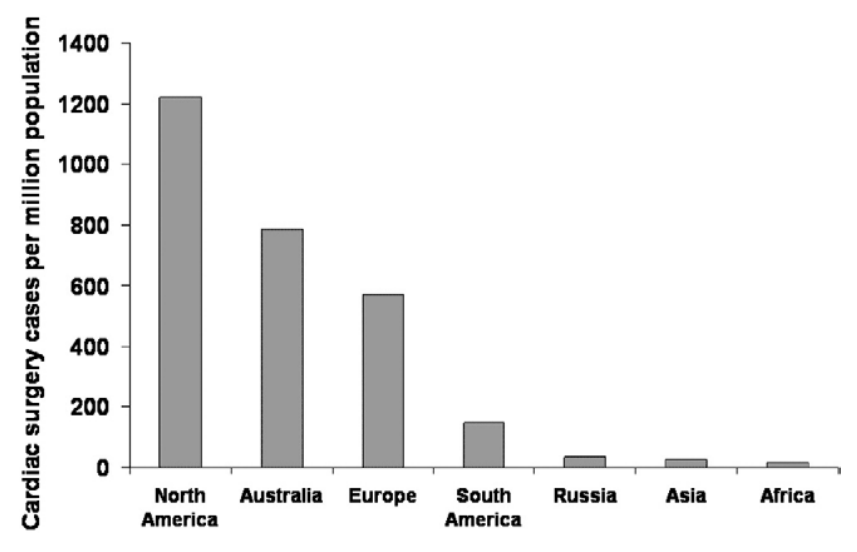

Figure 22. A worldwide survey on cardiac interventions in 1995 documented that many countries globally were tremendously underserved for cardiac surgery at that time. Source: Cox JL. Presidential address: Changing boundaries. J Thorac Cardiovasc Surg. 2001;122:413-8. Reprinted with permission of The American Association for Thoracic Surgery.

reality is that within the United States and most developed countries fetal diagnosis has not had a large impact on the incidence of congenital heart disease. Widespread use of echocardiography, in fact, has resulted in earlier and more complete diagnosis of salvageable heart problems in children. Earlier recognition of congenital heart disease is eliminating the scourge of pulmonary vascular obstructive disease, which is making surgery available for a much greater percentage of the world's children with congenital heart disease than in the past. And the cumulative population of adults with congenital heart disease is also increasing the workload for many congenital heart programs. Perhaps ultimately an improved understanding of the genetic basis of congenital heart disease will eliminate the specialty entirely, but at this point such an eventuality remains beyond the horizon.

\section{Implications of Increased Cardiovascular Disease and Cancer for Future Manpower Needs for Cardiothoracic Surgery}

How will an increased global burden of cardiovascular disease and cancer affect the manpower needs of our specialty? There is no international organization that has the resources to estimate the total number of cardiothoracic surgical procedures that will be performed globally in 10, 20, and 30 years. The World Health Organization has enough on its plate attempting to define, for example, the risks of a global pandemic of avian flu virus. The question is further complicated by wide disparities in the rates of cardiothoracic surgical procedures performed in various countries as documented by Dr Jim Cox ${ }^{7}$ in his presidential address to this Association in 2001.
In 1995 there were 1222 open heart surgical procedures per million population in the United States. The only country that approached that level was Australia, with 786 procedures per million. And while the rate of 1222 per million, which was measured before the impact of coated coronary stents, represents a high-water mark that may never be matched again, it is also clear that many countries in the survey were dramatically underserved. This is an additional factor needed for accurate estimation of the coming expansion of global cardiothoracic services (Figure 22).

\section{Rationalization of Global Distribution}

Let us now examine some of the barriers that inhibit appropriate global distribution of cardiothoracic surgeons, the matching of supply and demand. One of the important efficiencies that is introduced by economic globalization is a rationalization of the distribution of goods and services through elimination of trade barriers. Obviously, it would make little sense for each of the 50 states of the United States to be totally self-sufficient and responsible for its own food supply. Likewise, we would consider it absurd that surgeons trained in Massachusetts could only ever practice within the state of Massachusetts. The problem of appropriate matching of supply and demand becomes particularly challenging as a service sector becomes increasingly subspecialized, such as is the case for cardiothoracic surgery. Within congenital cardiac surgery, the problem of matching supply and demand on a global scale has resulted in an interesting distribution of surgeons around the planet, often working in locations that are quite remote from their institution of training. My move halfway around the world is not unusual in our subspecialty of congenital cardiac surgery. For example, Dr Christian Brizard from Paris, France, is the director of the congenital heart surgical program in Melbourne, Australia. But as I can personally testify, individuals who have made such moves have done so only with the greatest difficulty because of many bureaucratic barriers related to specialty certification and visas. Surely within our tiny subspecialty, which comprises perhaps only 200 in the United States and I would guess no more than 1000 dedicated congenital cardiac surgeons globally, it would make sense to establish a system of global certification that would facilitate the movement of congenital heart surgeons from areas of contracting to expanding need. Toward this end, the AATS Council has recently agreed to support my initiative to legally incorporate a global council for the development of educational standards for congenital cardiac surgical training. This is a first step in a process of international certification of congenital cardiac surgeons. And ultimately it is a step that I believe will make sense for the other subspecialty areas within cardiothoracic surgery.

What are the implications of a global mismatch of cardiothoracic surgical supply and demand for surgical training 
programs in the United States? From the perspective of recent graduates of cardiothoracic surgical training programs, we are currently in a state of labor oversupply. We are faced with a drastic reduction in applicants to train to be cardiothoracic surgeons. However, as demand for cardiothoracic services begins to rise in the United States in the near future, and as the supply of graduating surgeons begins to fall in exactly the same time frame, it is quite likely that there will be a considerable undersupply of surgeons in approximately 5 to 10 years. It is important that the extensive US training system that is currently in place not be dismantled because it will soon be needed. And that same system could play a helpful role in supplementing the education of the many surgeons who are already needed in countries like India and China, where demand is already expanding rapidly.

However, right now there are considerable visa and licensing challenges for cardiothoracic surgical trainees to come to the United States. Surely we in the United States should be welcoming foreign medical graduates who will have plenty of opportunities in their home country when they complete their fellowship. The Educational Council for Foreign Medical Graduates must expand the sponsoring of non-Accreditation Council for Graduate Medical Education accredited fellows for J1 visas, which should be facilitated rather than discouraged by the Immigration and Naturalization Service and US embassies abroad.

\section{Financial Implications}

What implications does globalization have for the personal financial outlook for cardiothoracic surgeons? How will an expanded pool of cardiothoracic surgeons globally affect your hip pocket? According to the economist William Baumol, who has formulated the so-called Baumol law, service occupations such as medicine, nursing, and surgery are inherently inflationary because they are labor intensive. ${ }^{8}$ For society as a whole, a source of increased economic wealth over time is the substitution of capital for labor. This is the very definition of rising productivity. The surgeon who performed 300 procedures in 1980 and 300 procedures in 2006 expects his real income to at least match the rise in the cost of living. However, since his productivity is unchanged and his real income has increased, he has contributed to inflation. But will an increasing pool of surgeons globally trained and certified to step into any position that becomes available result in falling compensation for surgeons. I believe there is a consensus among the economists that I have read that this is not likely to be the case. In a globalizing world, skills matter more than ever. ${ }^{8,9}$ While the wages and benefits of unskilled US steel and auto workers are falling toward global norms, in general Americans with high skills in contrast are being increasingly highly compensated. Globalization allows highly skilled Americans

\section{The Washington Consensus}

- Fiscal discipline, curb budget deficits

- Reduce public expenditure

- Tax reform

- Interest rates determined by market

- Competitive exchange rates

- Trade liberalization

- Promote foreign direct investment

- Privatization of state enterprises

- Deregulation of the economy

- Protection of property rights

Figure 23. The structural adjustment programs applied by the International Monetary Fund and World Bank from the early 1990s are based on the "Washington consensus." Data were obtained from "Social development-Debating the Washington consensus" available at (http://web.worldbank.org/WBSITE/EXTERNAL/ TOPICS/EXTSOCIALDEVELOPMENT/0,,contentMDK:20116211 menuPK:199474 pagePK:64020865 piPK:149114 theSitePK:244363, 00.html).

and others to offer those skills to the entire world rather than just locally. Furthermore, skilled workers in high income nations are paid not just on the basis of their productivity but also on the basis of local living costs and social norms of fairness. Americans prize health care greatly and many citizens today will aggressively search out the best health care. As economic conditions improve in Second and Third World countries, health is likely to become increasingly highly valued, and this will be reflected in the compensation that various societies globally will be prepared to pay for the best in health care.

\section{Risks of Globalization}

Although globalization offers the global cardiothoracic community the potential for generous rewards, there are also important risks and responsibilities that we should be aware of, both as physicians and as human beings. Beginning in the1990s, the International Monetary Fund and World Bank began to rigorously apply "structural adjustment programs" as a condition of supplying loans to developing countries. ${ }^{6}$ The basis for the structural adjustment programs is the "Washington consensus," appropriately named because there is little doubt that the United States is 


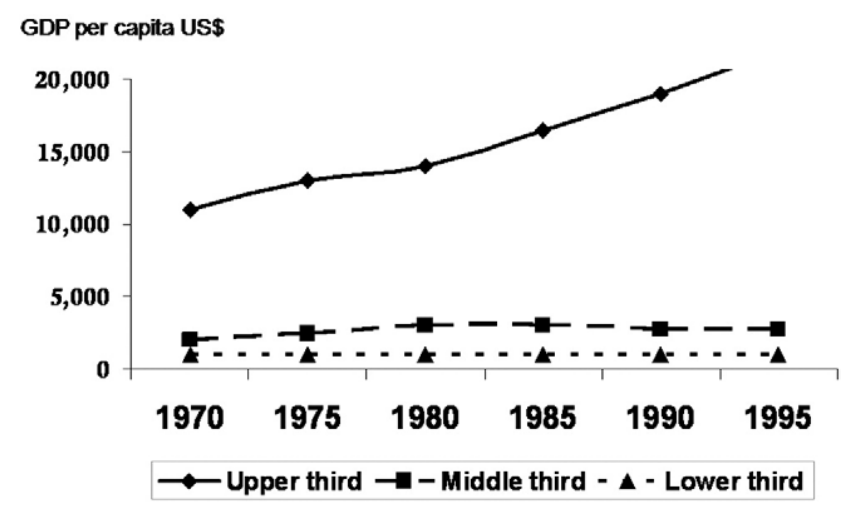

Figure 24. Although the most wealthy nations have benefited from tremendous economic expansion between 1970 and 1995, there have been few gains for the middle and bottom two thirds of countries globally. GDP, Gross domestic product. Data were obtained from the World Economic Outlook Database, available at www.imf.org

the dominant power in the International Monetary Fund and the World Bank (Figure 23).

\section{Global Health and Globalization}

Two of the requirements of the structural adjustment programs promulgated by the International Monetary Fund and World Bank have been reduction of public expenditure and privatization of state enterprises, including public health departments. However, a process of privatization requires strong government regulation as the World Bank itself has pointed out. There may also be a minimum population below which such policies are ineffective or even counterproductive. ${ }^{10,11}$ Many smaller countries, such as Jamaica, for example, have experienced a deterioration in health care delivery as they were forced to make a decision between taking international loans and continuing governmentfunded public health clinics. ${ }^{12}$ There has also been a strong response to the TRIPS agreement, which is now enforced by the World Trade Organization. TRIPS refers to trade-related aspects of intellectual property rights, which protects pharmaceutical patents for a period of 20 years. The TRIPS agreement, which has led to a substantial increase in the cost of pharmaceuticals as generic equivalents have been eliminated, has become a lightning rod that has united those who believe that the economic benefits of globalization are not being shared equally.

In 1997, developing countries paid a combined 292 billion dollars in debt service while receiving only 269 billion in new loans. ${ }^{6}$ Even individuals from within the World Bank, such as Nobel prize winner Joseph Stiglitz, ${ }^{13}$ who was chief economist at the Bank between 1997 and 2000, have argued that current policies of globalization have un-

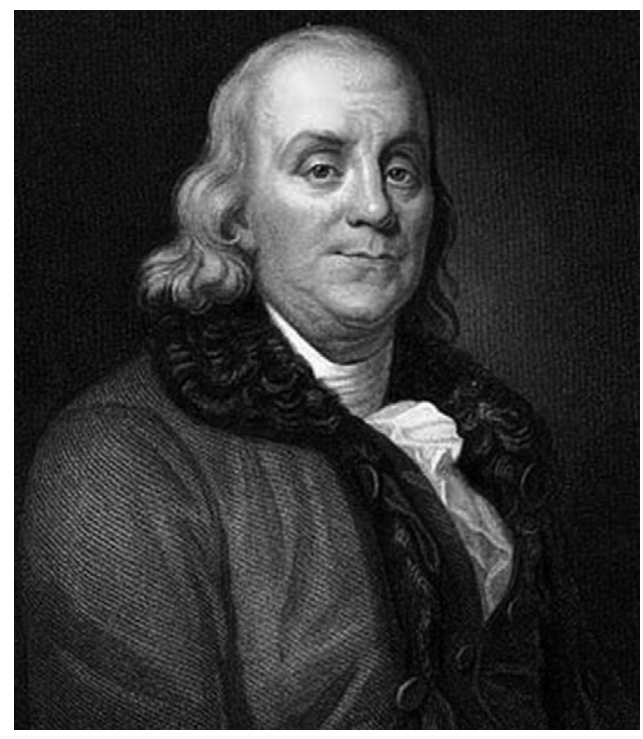

Figure 25. Benjamin Franklin, quintessential American, one of the authors of the Declaration of Independence, was also a globalist responsible for a number of diplomatic initiatives. Reprinted from earlyamerica.com

fairly benefited the wealthy nations while making only the most miniscule gains for the poorest nations. Although it is true that the number of individuals around the world living on less than $\$ 1$ per day has decreased, the number living on less than $\$ 2$ per day has substantially increased. In other words, current policy has simply taken the excruciatingly poor and made them painfully poor. ${ }^{6}$ In contrast, the most wealthy third of countries have benefited from tremendous economic expansion over the 25 years between 1970 and 1995 (Figure 24). Stiglitz ${ }^{13}$ and others ${ }^{14}$ would argue that these diverging lines begin to answer the question being asked in the developed world with increasing frequency in recent years: "Where does this global unrest come from?"

Ladies and gentleman, thank you for your attention this morning. Thank you for coming to the annual scientific meeting of The American Association for Thoracic Surgery. Thank you for coming to the great city of Philadelphia, which this year is celebrating the 300th anniversary of the birth of one of the great founding fathers of this nation, born in Boston but living most of his life in Philadelphia. Benjamin Franklin (Figure 25) was a quintessential American, not only a scientific innovator but also a great business entrepreneur. But in addition, Franklin was a globalist. ${ }^{15} \mathrm{He}$ spent many years living in London and subsequently in Paris, where he played a critical role in international diplomacy. And at age 70, back in Philadelphia, Benjamin Franklin assisted Thomas Jefferson in writing that great document, the Declaration of Independence, which as we all 
know begins: "We hold these Truths to be self-evident, that all men are created equal, that they are endowed by their Creator with certain unalienable Rights, that among these are Life, Liberty and the pursuit of Happiness." As cardiothoracic surgeons, we would all do well to emulate Franklin's energy, innovation, and entrepreneurial spirit. And as human beings, we have a responsibility to strive for a reasonable and equitable distribution of the benefits of globalization for all.

\section{References}

1. Bhagwati J. In defense of globalization. New York: Oxford University Press; 2004.

2. Wolf M. Why globalization works. New Haven: Yale University Press; 2005.

3. Murray CJL, Lopez AD. Evidence-based health policy-lessons from the Global Burden of Disease study. Science. 1996:274:740-3.

4. Magee M. Health politics: power, populism and health. Bronxville [NY]. Spencer Books; 2005.
5. Harris R, Seid M. Globalization and health. Boston: Brill Academic Publishers; 2004. p. 223.

6. Stieger, M. Globalization: a very short introduction. New York: Oxford University Press; 2003. p. 72.

7. Cox JL. Presidential address: changing boundaries. J Thorac Cardiovasc Surg. 2001;122:413-4.

8. Kuttner R. Everything for sale: the virtues and limits of markets. Chicago: University of Chicago Press; 1999. p. 117.

9. Friedman T. The lexus and the olive tree: understanding globalization. New York. Farrar, Strauss Giroux; 1999.

10. Garrett L. Betrayal of trust: the collapse of global public health. New York: Hyperion; 2000.

11. Lee K, Buse K, Fustukian S. Health policy in a globalizing world. Cambridge [UK]. Cambridge University Press; 2002.

12. Life in debt. A film by Stephanie Glack. USA. 2001. Available from www.lifeanddebt.com.

13. Stiglitz J. Globalization and its discontents. New York: WW Norton; 2003.

14. Cavanagh J, Mander J. Alternatives to economic globalization: a better world is possible. San Francisco: Berrett-Koehler Publishers; 2004.

15. Wood GS. The Americanization of Benjamin Franklin. New York: The Penguin Press; 2004. 